An Interdisciplinary Approach to Examining

the Working Conditions of

Women Coaches

by

Justine B. Allen and Sally Shaw

Reprinted from

International Journal of

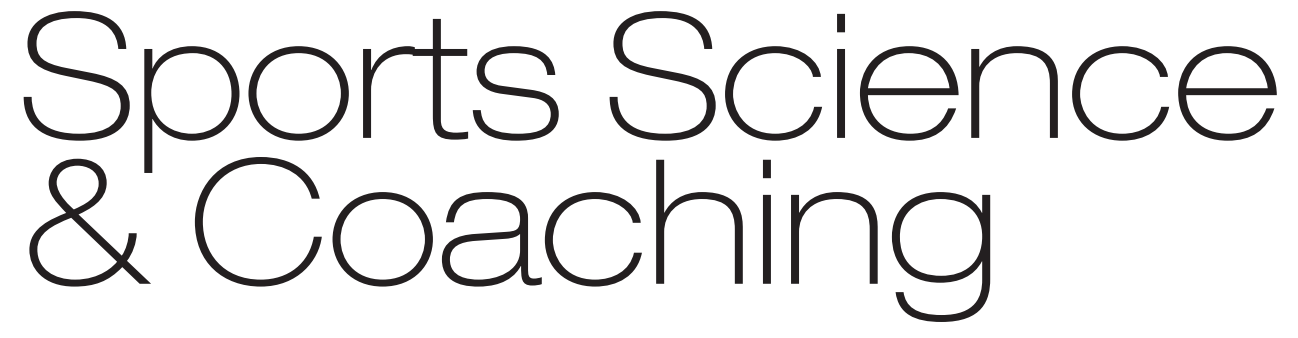

Volume 8 - Number $1 \cdot 2013$ 


\title{
An Interdisciplinary Approach to Examining the Working Conditions of Women Coaches
}

\author{
Justine B. Allen ${ }^{1}$ and Sally Shaw ${ }^{2}$ \\ ${ }^{1}$ University of Stirling, School of Sport, \\ Stirling, FK9 4LA, UK \\ E-mail: justine.allen@stir.ac.uk \\ ${ }^{2}$ University of Otago
}

\begin{abstract}
An interdisciplinary framework allowed psychological and sociological approaches to be combined to examine coaches' working conditions, specifically to examine the structural aspects and social values within the sport organisations as well as the implications for individual aspects. Ten participants from two sport organisations took part in the study. They were eight women performance coaches and two coach managers. Participants were interviewed to explore their perceptions of the working environment in their sport organisation including involvement, support, opportunities, and relationships. Four themes were developed characterising coaches' perceptions of their working conditions. These were relationships with key organisational personnel, coach as a person, learning and development opportunities, and relationships among coaches. The themes were examined both within and between the two sport organisations. The structures and values of one organisation fostered working conditions conducive to the need satisfaction of the coaches. The working conditions within the second organisation were less effective, but reflected its organisational values. The findings are discussed in relation to coaching research and provide an alternative approach to examining the social context of coaching.
\end{abstract}

Key words: Gender, Organisational Values, Self-Determination Theory, Sports Management, Women Coaches, Working Conditions

\section{INTRODUCTION}

Coaching is a complex socially situated process and yet little is known about the social context in which coaches operate [1,2]. This study adopted Dixon and Bruening's [3] interdisciplinary framework to examine coaches' working conditions [4] within their sport organisations.

Reviewers: Kitrina Douglas (University of Bristol, UK)

Cindra Kamphoff (Minnesota State University, USA)

Leanne Norman (Leeds Metropolitan University, UK) 
The under-representation of women as coaches and in particular in higher level coaching roles has been well documented [5-7]. Much of the related research about female coaches has either examined large numbers of participants (e.g., [5]) or the participants are spread over large numbers of organisations, geographical areas, or sports $[8,9]$. Studies have also tended to focus on the difficulties faced by women, which are many, in comparison to men $[6,10]$. One difficulty has been career development. Research has demonstrated this can be affected by organisational factors including perceptions of the lack of a clear or logical pathway, fewer opportunities compared with men to work as leader or coaches in sport, less support from governing bodies for their development, selection processes based on the 'best' (male characteristics) person for the job $[6,11]$. The above research has provided invaluable insight into the experiences of women coaches, but little attention has been given to the day-to-day working conditions of coaches and the perspectives of coach managers. The present study sought to examine coaches' and managers' perceptions of the social contexts women coaches operate within. We adopted an interdisciplinary approach using Dixon and Bruening's [3] framework to structure our exploration of the working conditions of women performance coaches. Kelchtermans and Ballet's [4] concept of working conditions was used to encapsulate aspects of the social working environment that may influence coaches working in sport organisations. Self-determination theory [12] was used to explain the relationships among working conditions and implications for coaches.

\section{WORKING CONDITIONS}

Despite growing recognition of the complexity of coaching and the need to investigate the relationships between coaches and the environment $[1,2,13]$, little attention has been given to examining the context in which coaching occurs. To date, where contextual factors have been identified as influencing the coaching process, the focus has been on identifying specific aspects of the social context as explanations for particular actions of coaches (e.g., [14-16]). Much less attention has been given to the social contexts coaches operate within or coaches' perceptions of these environments.

Drawing from research examining teachers' professional development, Kelchtermans and Ballet [4] used the concept of 'working conditions' to capture participants' experiences within their work organisation (school). They argued that people hold beliefs about the working conditions that are necessary or desirable to perform their tasks in a manner that is both effective (i.e., achieves desired outcomes) and satisfying to the participant. A central feature of the working conditions that were highly valued by the participants in their study was the quality of interpersonal relationships in and around the organisation. Opportunities to share concerns or discuss teaching questions and a sense of being appreciated by the principal and colleagues were important features of quality relationships within the organisation. The concept of working conditions may enable coaching researchers to gain insight into the social context of sport organisations [13]. For example, understanding the interpersonal relationships, values, and organisational structures that shape coaches' working conditions in sport organisations may provide insight into how opportunities and constraints are created that influence coaches' work and satisfaction within their organisation.

\section{AN INTERDISCIPLINARY APPROACH}

Dixon and Bruening [3] called for an integrated approach to understanding experiences within sport organisations. They argued that in order to develop an understanding of these experiences, it is necessary to examine the individual and structural aspects of sport organisations along with the social values within the organisation. We adopted this 
framework as it provided an opportunity to integrate psychological and organisational approaches to examine coaches' perceptions of working within their sport organisations and gain insight into managers' perspectives. In doing so, we recognise that there is overlap and inter-play between the various aspects of Dixon and Bruening's approach. In the interests of clarity, we present the different levels as discrete.

\section{INDIVIDUAL}

In order to address the individual aspect of Dixon and Bruening's framework [3], we adopted Self Determination Theory (SDT) [12]. This approach has proven useful in understanding the social contextual factors associated with individuals' optimal functioning and development. It posits that the satisfaction of individual psychological needs is a necessary requirement for psychological well-being and that the social environment can foster or thwart satisfaction of these needs. Three psychological needs are central to SDT. These are the need for autonomy, to feel at the origin of one's behaviour; the need for competence, to feel effective in one's dealings with the environment; and the need for relatedness, to feel connected with one's social world [12]. Working conditions that are characterised by managerial support for employees as individuals such as acknowledging subordinates' perspectives, offering choice, and encouraging self-initiation have been associated with the satisfaction of workers' needs for autonomy, competence, and relatedness [17,18]. In relation to coaching, recent research has demonstrated that coaches' psychological need satisfaction was related to their experiences of well-being which in turn was related to their use of autonomy supportive coaching behaviours with their athletes [19]. Therefore, SDT provided a useful theory to guide our examination of coaches' perceptions of their working conditions and, in particular, the quality of relationships within their sport organisations and coaches' psychological need satisfaction.

\section{STRUCTURAL}

In their framework, Dixon and Bruening [3] define structural aspects as the formal attempts to define organisational life (i.e., working conditions). These considerations include policies, programs, and organisational regulations. At this structural level, a broader sociological approach also becomes useful in understanding performance coaches' perceptions of their experiences. That is, by examining the processes that go into the development of organisational structures, and employees' or volunteers' interpretations of policies and programs, it is possible to better understand how organisational constraint and opportunity are created $[20,21]$. In terms of women coaches, structures might include women in coaching programmes or affirmative action-type policies. With regard to career development of women coaches, there appears to be an assumption that opportunities are equally available to all coaches. Research on women coaches' career pathways suggests that, at least for women, this may not be the case $[6,11]$. Furthermore, managers' perspectives on working with coaches in their organisations have received little attention. For example, North [22] examined men and women coaches' perspectives of coach development officers' service provision. Similarly, Bruening and Dixon's multiple studies have provided in-depth data on women coaches' perspectives on administrators' roles. However, the managers in these studies are silent. By including coach development managers' intentions, researchers may be able to gain insight into how the working conditions in organisations are constructed with regard to women performance coaches. Specifically, this will address issues such as organisational structure and values and the influence on the availability and access to learning opportunities as social contextual constraints or opportunities for coaches' development. 
SDT can also assist in the understanding of organisational structures because it offers the opportunity to examine whether individual needs are satisfied, or even recognised, in the development of organisational structures and organisational life. In this way, we may examine not only how structures are a mirror of organisational working conditions but also how they are used to knowingly or unknowingly construct the realities of female performance coaches' experiences. For example, for some women, affirmative action policy may present opportunities to have access to learning and development that would otherwise not be the case and therefore have positive meaning for coaches and managers in the organisation. Conversely, as a result of the policy, the female coach may face envy from her peers and any promotion through the sport's coaching echelons may be perceived as favouritism or reverse sexism [23]. The influence of a policy that influences organisational structure thus shapes certain working conditions which shapes and is shaped by coaches' experiences.

\section{SOCIETAL AND ORGANISATIONAL VALUES}

Finally, Dixon and Bruening [3] suggest that societal and organisational values need to be examined in conjunction with organisational structures. Hoeber and Frisby [24] and Hoeber [25] have argued that organisational values are fragmented, with different meanings and influence attributed to them. Values are influential, as they encourage employees and volunteers to think and act in certain ways within their organisations. However, they are also fluid, and can be influenced and altered. It is important, therefore, to investigate the values that underpin women coaches' management. It is also useful to examine how the coaches themselves define, identify, and support various values within their organisations that shape their working conditions.

\section{SUMMARY}

Despite efforts to better understand the factors associated with the under-representation of women in coaching, little attention has been given to the day-to-day working conditions coaches' experience. Therefore, the purpose of this research was to investigate coaches' and managers' perceptions of the working conditions for women performance coaches in two sport organisations. Kelchtermans and Ballet's [4] concept of working conditions was used to capture participants' perceptions of their experiences in their organisation. To develop the concept of working conditions further we used Dixon and Bruening's framework [3]. This framework offered an opportunity to combine psychological and organisational sociological approaches in an interdisciplinary approach that allowed us to present a broader picture of the working conditions of women who coach performance sport. As such, it offers insights into the social contexts of sport organisations which form an integral part of the coaching process.

\section{METHOD}

\section{PARTICIPANTS}

Performance coaching has been characterised by its emphasis on competition within an organised competition structure and an intense commitment to preparation programmes with specific competition goals [26]. Performance coaches were chosen for this study because it is when women begin to compete for coaching jobs at representative or professional levels that their numbers dwindle $[5,7,10]$. Furthermore, the documented international underrepresentation of women in performance coaching (e.g., [27-29]) is also reflected in New Zealand, where the present study was conducted. For example, at the 2008 Olympics in 
Beijing, New Zealand women were under-represented in coaching roles relative to the number of women athletes. Only $3(7 \%)$ of the 43 coaches were women compared with $46.7 \%$ of the competing athletes [30]. At the 2012 Olympics in London, in the New Zealand Team there was a similar proportion of women athletes competing $(46.5 \%)$. However, women were again under-represented in coaching. Although overall there were more officials in the 2012 team compared with in 2008, only 3 of the coaches were women [31].

Ten participants took part in the study. Eight were women performance coaches from two Regional Sports Organisations (RSOs) in one region of New Zealand. Two participants were the coach development managers (CDMs) from the two organisations. The coaches were either currently or had recently worked with athletes on the performance pathway of their sport. The performance pathways included athletes who had been selected to represent their region (similar to competing for a state or province) at age group or senior (open) competition level. The ethnicity of the coaches' was White. Their age, experience, and qualifications are presented in Table 1. The coaches ranged in age from 28 to 54 years $(\mathrm{M}=$ 40.1 years). Their total years of coaching experience ranged from 7 to 17 years $(\mathrm{M}=12.4$ years). All participants had completed at least Level 2 of a national three-level coaching qualification program in their sport. This level of qualification is commensurate with their role as performance coaches. Seven of the coaches had also attended additional coach education opportunities such as conferences, short courses, and seminars. Only one of the eight coaches was employed as a coach, the other seven were volunteer coaches. Five of the volunteer coaches were employed in secondary or tertiary education. The coach development manager for each RSO also participated in the study. The CDM of WomOrg was in her mid40 s and had been in the role for five years. The CDM of MixOrg was in his mid-50s and had been in the role for eight years.

Table 1. Coaches' Demographic Information

\begin{tabular}{lllll} 
& Age (years) & $\begin{array}{l}\text { Coaching } \\
\text { Experience } \\
\text { (years) }\end{array}$ & $\begin{array}{l}\text { Coaching } \\
\text { Level }\end{array}$ & $\begin{array}{l}\text { Coaching } \\
\text { Qualifications }\end{array}$ \\
\hline MixOrg & & & & \\
\hline Jane & 28 & 7 & U18 & Level 2 \\
\hline Glenys & 46 & 15 & U18 & Level 2 \\
\hline Lara & 37 & 11 & U21/Senior & Level 3 \\
\hline Fay & 45 & 12 & Senior & Level 2 \\
\hline
\end{tabular}

\begin{tabular}{lllll}
\hline WomOrg & & & & \\
\hline Kath & 43 & 14 & U19 & Level 3 \\
\hline Raewyn & 54 & 12 & U19/Senior & Level 2 \\
\hline Jackie & 32 & 11 & U21 & Level 2 \\
\hline Pat & 36 & 17 & Senior & Level 3 \\
\hline
\end{tabular}

\section{PROCEDURE}

Two Regional Sport Organisations (RSOs) were purposively selected because of their differences in numbers and retention of women performance coaches. One organisation represented a sport with a participant base of both women and men and a low proportion of women coaches (MixOrg). The second organisation represented a sport played predominantly by women and a large proportion of women coaches (WomOrg). Purposive 
criterion sampling was used to identify potential participants for the study [32]. RSOs identified female performance coaches who were either coaching or had coached at the regional under 18/19 years, under 21years, or Open level in the last three years. Four coaches and the coach development manager from each organisation were invited to participate in the study. All eight coaches and the two managers agreed to participate. Interviews were conducted at a location of the participants' choice and lasted approximately 60 minutes. In keeping with our tertiary institutions' ethical procedures regarding confidentiality, all participants were given a pseudonym and the organisations were referred to as MixOrg and WomOrg.

\section{DATA COLLECTION}

Interviews were conducted to examine coaches' and managers' perceptions of the working conditions for women performance coaches in their organisations. Specific attention was given to perceptions of the interpersonal relationships, organisational values, and structures within the RSO. Participants were invited to participate in the interviews by telephone, were provided with an overview of the research, and given an indication of the purpose of the interviews. Interviews were semi-structured to provide rich, informative description of the coaches' and managers' views [33, 34]. The interview comprised topics to be discussed and included specific questions and probes which varied as the conversation developed [33, 34]. The interview questions were designed to encourage the participants to describe their perceptions of the working conditions within their RSO. The invitational phone calls and semi-structured process allowed rapport to develop between the interviewer and participant which encouraged the expression of the participant's point of view [33].

In order to address the individual and structural aspects of coaches' working conditions, the interviewees were asked to describe their experiences of coaching (or working with women coaches) within their organisation. To gain insight into the values regarding organisational structures and beliefs, the interview guide was supplemented by more general questions. The questions included asking participants to describe what their organisation values in its coaches and what opportunities were provided to feedback to the organisation. To ascertain individual aspects relating to need satisfaction and the social context, questions were asked regarding the support coaches' received, opportunities for development, career pathways for women coaches, relationships with key RSO personnel, and relationships with other coaches.

\section{DATA ANALYSIS}

The interviews were audio tape recorded and transcribed in full. Transcripts were offered to all participants for review and to provide additional comments. All participants indicated that through the interviews they had ample opportunity to express their views and did not add anything further. We were therefore unable to undertake member checks with participants. The transcripts were compared with research notes that had been made by the researchers immediately after each interview. For example, we noted participants' body language, or if there were long pauses in an answer that indicated a lot of thought. This ensured data-source triangulation [35].

The data were analysed through a combination of open and axial coding. For the individual and structural aspects of the participants' perceptions of the working conditions, the tenets of SDT provided a framework for analysis. The data were analysed axially for evidence of support for autonomy, competence and relatedness. However, with the interdisciplinary agenda in mind, the data were also independently coded by the two 
researchers in an open approach. In this process, the data were analysed for features that could give insight into the fluid, discursive nature of organisational values and structures that shape the coaches' working conditions. The discussions within this process added to the credibility of our analysis as we would question our interpretations of the data to ensure that we had understood the respondents' replies. The researchers examined the data for commonalities, contrasts and tensions. For example, comparison was made between the coaches' and coach managers' comments, that is, we identified what a coach had said about a topic and then compared the coach manager's comments and vice versa.

The researchers conducted this initial phase of data analysis independently and then discussed their findings, reaching agreement on the themes present in the data. The data were initially organised into thirteen themes, which gave insight into a broad overview of the experiences of performance coaches. These themes were then re-analysed looking to develop more robust analytical categories with a greater richness of data. This process was achieved by discussing Bruening and Dixon's framework [3] and reminding ourselves that we wanted to understand the individual, structural, and values aspects of the coaches' working conditions, within the boundaries of psychological and sociological approaches. After this second phase of data analysis, the initial thirteen themes were reduced to four. Through this process, we ensured the trustworthiness of the data by employing data-source triangulation methods (using our research notes), investigator triangulation (by examining the data independently and then discussing), and theory triangulation (using our theoretical framework to assist in analysis) [35]. While it would have been ideal to include the participants in this process, they were not willing to be involved, so these triangulation processes served to verify our analysis and ensure consistency.

Using Dixon and Bruening's framework, we organised the data into four themes which most closely helped us to address our research question and also provided an accurate analysis. The following four themes were developed: relationships with key RSO personnel, coach as a person, learning and development opportunities, and relationships among coaches.

\section{RESULTS AND DISCUSSION}

The four themes that characterised participants' perceptions of the working conditions within their sport organisations are described separately. Illustrative quotes are used to depict the coaches' experiences. Then the theme is discussed in relation to relevant literature. To avoid repetition and to make the most sense out of the data, the working conditions are discussed within the three levels of Dixon and Bruening's framework [3]. Structural aspects are discussed first. Then the social values of the organisations are examined for how they might contribute to the development of these structures. Finally the implications of these structures and values are discussed at the individual level. In this discussion, the working conditions of the two organisations are compared and contrasted. Although the themes are presented separately, there is overlap and inter-play between the themes and between the three levels of Dixon and Bruening's framework.

\section{RELATIONSHIPS WITH KEY RSO PERSONNEL}

This theme captured participants' perceptions of the quality and implications of relationships between coaches and organisation personnel. When it came to the coaches' work with athletes all coaches felt they worked independently from their organisation. As Jackie noted "in terms of our planning and the way the team runs they [WomOrg] don't have any involvement". Glenys' comments indicate that the independence was similar in MixOrg 
"once you get your time you know your [practice] bookings, you just go on doing your thing". The level of independence was reinforced by the coach managers. Nick stated that he took a "hands off approach" (MixOrg). Anna noted "I let them run their team. We've selected them on their skills and we let them go on their merry way, it's their team. They're the coach" (WomOrg).

Despite similarities in the approaches the organisations took when it came to the coaches' work with the athletes, there were clear contrasts in their structural approach to relationships with key personnel. Nick from MixOrg was sure that he was doing all he could to support the coaches. Although acknowledging his hands off approach, he also noted "I do a lot. I've fed them resources, keep in touch all the time and support them as well as I can". The coaches did not agree. They felt there was little contact or interest in them once they had been appointed. Fay made the comment "I mean I don't know if the organisation would even care if I wasn't there". Glenys also elaborated on her experiences "It's the reality. They don't really do much for the coaches. As long as they've got somebody in that slot taking a team, they're not really too worried... they're not really encouraging people." In contrast, Anna from WomOrg also left the coaching to the coaches, but she noted the importance of taking account of coaches' perspectives and asking them how the organisation could better support them. The coaches recognised and appreciated the relatively open communication with and support from key personnel in the organisation. Pat reiterated the importance of key personnel making coaches feel wanted and useful, saying "I think making sure people feel valued is huge ...I think just recognising and thanking people is huge". Raewyn commented on the support offered:

I think just knowing that they are there for you, if you need the help they certainly will help you...[CEO] pops in from time to time ...they're always asking how it's going, is everything OK, is there anything that you need, you know, we want to help you.

Organisational Structures. Scully [36] and Fine [37] noted that it is important that organisational structures enable open communication to ensure that members feel that they are a valued part of the organisation. All the coaches felt that they were able to work independently and were satisfied with this freedom. However, in MixOrg the coaches were far from satisfied with their relationships and communications with key organisation personnel. Nick did not enable two-way communication which undermined his relationship with the coaches. The coaches felt that key people in the organisation had little interest in them, their athletes, or their coaching activities. This indicated that there were no formal processes by which key organisational personnel kept in touch with their coaches, thus affecting the quality of the relationship with the coaches. Norman's findings [6] also suggest that communication between women coaches and their organisations are important to coaches. She noted that coaches did not feel their knowledge and skills were being used effectively and consequently they did not feel a valued part of the organisation, an argument that is reflected in our findings. In contrast, WomOrg coaches had closer connections with the CEO, administrator, and coach manager. These more open structures ensured that the coaches felt that their efforts were recognised and valued and they were, to some degree, part of the organisation.

Organisational Values. As an organisational value, relationships with key personnel were clearly very important to all the coaches and to personnel in WomOrg. As Dixon and Bruening [3] note, organisational values are informed by experiences. Those who have a 
good relationship, mainly in WomOrg, relished that communication and the support it provides. Over time, positive experiences ensure that the value within the organisation develops to be an important and beneficial one. Pat was clear that this relationship should not be taken for granted and that the continuation of the organisation showing gratitude was central to maintaining good relationships. Where this had not occurred, largely in MixOrg, the levels of commitment and interest from the coaches were far less evident. Nick's 'arm's length support' and lack of proactivity contributed to working conditions that seemed to undermine the interpersonal relationships that the coaches had with the key personnel in the organisation.

Individual Aspects. At the individual level of analysis, the findings from this study indicate that the relationships with key personnel are important for satisfaction of coaches' sense of autonomy and relatedness. Gagné [17] described an environment that fosters satisfaction of the psychological needs for autonomy, competence, and relatedness as a context that operates "within a climate of relatedness". Although the 'hands off' approach in MixOrg may have satisfied the psychological need for autonomy it did not satisfy relatedness because coaches did not feel that key personnel were interested in them or valued their coaching. In contrast, the actions of key personnel in WomOrg were more consistent with autonomy supportive behaviours which have shown to foster need satisfaction in a range of settings including work [18]. Limited need satisfaction has potentially negative ramifications for individuals' well-being, functioning, and development [12] and for the quality of their work with athletes [19]. For example, Stebbings et al. [19] found that coaches who experienced greater need satisfaction also experienced a greater sense of well-being and were more likely to work with their athletes in an autonomy supportive manner.

\section{COACH AS A PERSON}

The 'coach as a person' theme was defined as recognising coaches as being more than 'just' a coach. In MixOrg, there were various comments about the lack of value other than being just someone to fill a coaching position. Glenys summed up this popular theme:

I guess at the end of the day they are thankful that somebody is putting the work in and taking their team... at the end of the day they're just quite happy for someone to be in that position and it's a position filled.

When questioned about the value of female coaches as people, Nick's approach highlighted the need to encourage them to avoid having chaperones for women's teams. He commented that "when there's a male coach, like Under 18 girls last year, there'd be a female manager, we've gotta make sure all those sorts of issues are dealt with." He could also see the value in increasing numbers of women coaches so that he had greater choice regarding coach selection and as he commented "so then you can hire and fire."

Fay felt the lack of value may be related to being female. She described how she felt women were overlooked for performance coaching roles. She said "they [the Board, the $\mathrm{CDM}$ ] think a good man player is better than a good girl player, so in their heads he will be better at explaining skills and tactics and I think they see men as more clever about [the sport]." Lara reiterated this comment with her own perspective on opinions regarding coaches, noting "Nick'll say they choose the best person for the job. But it's not transparent. They base their definition of 'best person' on their own qualities. And they're all men." It was not only gender that was considered to be problematic in terms of being valued as more than just a coach. Fay suggested that being overlooked for higher coaching honours was also 
in part due to the high value that was put on ex-international stars as coaches. "For me there hasn't been a pathway. Possibly because I never was [an international representative], like I had kids at 21. I mean if I was a [well known international player] I'm sure they would have put me through the ranks."

In WomOrg, the coaches' experiences were somewhat different. The strengths and weaknesses of the coaches were recognised and valued. Jackie noted that "they [WomOrg] recognise that the coaches are all individuals and have their own strengths too." Equally, Raewyn noted that "in terms of organisation and going away on trips and all the bits and pieces that goes with that they [WomOrg] are really proactive." The organisation was even willing to get extra funding for a specialist coaching apprenticeship because they valued the input that Jackie might have. She explained "they [WomOrg] could very well have said 'look we're giving it to Jake' ... but they were happy to seek funding for me as well."

Conversations about childcare highlighted how highly motherhood was valued as a part of the coaches' lives. Raewyn explained:

The sport is very accommodating with kids, or breastfeeding or whatever has to happen. I like that environment. Jackie's going to a tournament next week, and ... she's taking her wee boy with her. And I said look you'll be absolutely fine ... they are very supportive of that. Some of the courses I've been to there's babies there and ... it's OK to have your baby there.

Anna reiterated WomOrg's position by saying "with Jackie, she was breastfeeding and we were happy to make allowances. I haven't heard any negative comments about it."

Organisational Structures. In MixOrg, the coaches were of value to the organisation because they could fulfil structural obligations: to avoid using chaperones and providing choice, thus enabling the organisation to 'hire and fire'. There was no mention from Nick of a need to develop a strong base of coaches for the sake of the sport in the region. Kolb et al. [36] have argued that when gender relations are addressed in organisations for purely structural reasons, any short-term changes to gender relations are very hard to sustain. This is because structural approaches do not change the culture or informal practices within organisations. In contrast, in WomOrg, organisational structures were in place which ensured that coaches were valued. Firstly, assistance with organisational tasks ensured that the coaches could focus on coaching and have some time for their other commitments outside coaching. Secondly, the organisation's attempts to support women who were mothers ensured that structures were in place that valued coaches as women and mothers, not just as coaches.

Organisational Values. In MixOrg, coaches' recognised two characteristics were vital to being valued as more than 'just a coach': being a man and having an international sporting career. Without these, the coaches did not feel recognised as anything but functional coaches. These findings are consistent with research in which women coaches reported a gender bias in the value assigned to coaches privileging men and 'male' qualities over women that restricted opportunities for women coaches' development [6, 11]. In WomOrg there were also two key features to this organisational value, but they were quite different to those in MixOrg. WomOrg worked to remove the burden of organisational tasks so that coaches could focus on their work with the athletes and to value them as mothers who were coaches. Motherhood was considered to be part of their coaching persona, rather than a hindrance to it. Where the values of the organisation complement the structural approaches the working conditions created are likely to ensure sustainability within the organisation [38]. 
Individual Aspects. Acknowledging people's perspectives and recognising individual strengths and requirements is an important feature of a social context that supports psychological needs and desired work behaviours [18, 39, 40]. Compared with MixOrg, the coaches in WomOrg felt a greater sense of support for their coaching and value as people rather than 'just a coach'. The assistance offered by their organisation and the recognition that some coaches may need different support such as with childcare contributed to the coaches' feeling that their perspectives were acknowledged, they were valued as people, and consequently that their coaching autonomy was supported.

\section{LEARNING AND DEVELOPMENT OPPORTUNITIES}

This theme captured participants' perceptions of the learning and development opportunities in their sport. The respondents in MixOrg discussed a lack of coach development opportunities. Glenys stated that "it's quite limited and I feel the [Organisation] should be doing more to up- skill coaches... There's no interest either in taking coaches to the next step". Fay also noted that her age and gender worked against her, saying "there is no pathway. No. I might be old, might be female, but I am still developing". Glenys added that because she had been successful "there weren't a lot of people that would feel comfortable or would come and evaluate me because they would think, oh, I don't feel comfortable telling her what to do". Despite these comments, Nick was adamant that there was a clear pathway for coaches to up-skill. He commented that "most definitely...There is definitely a pathway there. Anyone who wants resources, information, or how to climb the pathway contacts me".

In contrast, the respondents from WomOrg were clear about their opportunities for coach development. Raewyn realised the importance of taking opportunities that were presented. She said: "I thought about it and thought well if I'm going to coach at a higher level I need to put myself out there, attend more of these courses. There are heaps and heaps available". It was also clear that the coach manager was integral in encouraging coaches to attend sessions. Jackie described how instrumental Anna, the coach manager, had been in developing coaches. Jackie said "she's always been a real encourager. She's always out there trying to get coaches to get their accreditation and everything." Three of the coaches had been through an apprentice coach initiative where they were part of a team but had no coaching responsibilities. Each of the coaches had high praise for the scheme and felt that the opportunity to learn from other coaches 'in situ' was invaluable. Raewyn commented: "because you don't [usually] get a chance to work with other coaches because you're too busy doing your own thing."

One coach, Pat, the most senior at WomOrg, felt the organisation could do more for the coaches' development. She recognised the importance of feedback saying "I just think you can't get better if you don't have the feedback". Pat had also initiated her own mentoring relationship because there was no formal mentor opportunities established within the organisation. She commented, "I've instigated my own mentor, she's fantastic and she'll come to trainings ... she's available to talk at any state so like, I found that really extremely valuable."

Organisational Structures. There were clear differences between the organisational structures regarding coach development opportunities for MixOrg and WomOrg that contributed to quite different working conditions for the coaches. Despite Nick's belief that there was a clear organisational pathway for coach development in MixOrg, the coaches were not aware of that pathway. There was, therefore, a disjuncture between the expectations of the coaches and the manager in developing a clear organisational pathway for coach development which created a level of tension between the coaches' and manager's 
perspectives. This finding reflects that of Fielding-Lloyd and Meân [21] who, in their analysis of gender equity programs in soccer, found that resistant discourses could undermine the potential of such programs. In contrast, in WomOrg, there were more consistent discourses regarding the nature of coaching pathways. Expectations between the coach manager and the coaches were more congruent leading to more favourable working conditions. WomOrg had both formal and informal approaches to up-skilling coaches, which most of the coaches felt worked well. The coach manager was aware of the importance of being proactive, finding new coaches and encouraging them to gain mentorship. The only coach who did not feel that the organisation did enough was Pat. Her experiences are similar to those of coaches in Norman's study [6] who suggested that when you are seen to be at the 'top of the tree' (i.e., an elite or very experienced coach) people tended not to give advice and opportunities for on-going professional development are less readily available. Glenys from MixOrg reported similar experiences due to her success.

Organisational Values. Examining coach development as an organisational value gives further insight into why and how these opportunities were developed. The coaches in Mix Org felt there was a lack of interest in seeing them develop as coaches. Their potential longterm contributions to the organisation and sport were not a priority. This was reinforced by a lack of proactivity surrounding 'coach development' which precluded the women in MixOrg from progressing. Organisations 'forgetting' to focus on development for coaches, i.e., not valuing, has been noted in the coaching literature [6]. In contrast in WomOrg, the organisational value of coach pathway development embraced a degree of proactivity and flexibility. The coach development manager recognised that she had a role to identify and nurture coaches, from high school through to the elite level. The organisational value of coach development was thus regarded highly within WomOrg by coaches and key personnel. Following Hoeber [25] the approach taken by WomOrg may well present a seemingly more complex, flexible scenario. However, our findings demonstrate that the working conditions within an organisation can shape the opportunities that are available to coaches. Organisational values around development and coaches as people were instrumental in facilitating access to development opportunities for coaches.

Individual Aspects. All coaches in this study expressed an interest in and desire for development opportunities. Two critical features of the social context that foster a sense of competence are training opportunities and feedback [18]. Coaches in WomOrg had many opportunities that contributed to their sense of competence. These included clear development pathways, access to a range of courses, and networks amongst coaches where they were able to gain feedback. However, only one coach had a mentor which she had organised herself. In contrast, coaches in MixOrg felt that none of these opportunities were available to them. As a result they felt there was a lack of support for their competence development as performance coaches. These findings are consistent with coach learning and development research which identifies the value coaches place on learning through interaction with other coaches [41, 42]. In addition, research in teaching indicates that the opportunity to share concerns and discuss work was a highly valued feature of teachers working conditions [4].

\section{RELATIONSHIPS AMONG COACHES}

This theme highlighted coaches' desire to interact frequently with each other for support and development. Consider the following comments from two of MixOrg's coaches. Fay noted: "I've noticed people are quite isolated ... you are so on your own ... I have absolutely nobody to talk to ... the isolation is unbelievable really." Jane made a similar comment 
saying "you're pretty much, I felt, there on your own ... it kinda is a bit of a men's club down there I guess. It's got that sorta atmosphere about it." The MixOrg coaches also noted that they did not know the other coaches in the organisation. Jane described the connection between coaches as "pretty non-existent" and said that "I'd see people at the [sport venue] I wouldn't really know who they were or what team they were coaching, it's pretty terrible really". When questioned about the need for coaches to interact regularly, Nick alluded to an annual 'thank you dinner' for the coaches, saying that it was "crucial, crucial ... vital. The more we can get networking the better". He was unable to provide any examples of ideas to promote more regular contact between the coaches.

In WomOrg, coaches faced the same isolation issues, with Pat noting that "in the end, coaching can be pretty lonely". However, unlike MixOrg, the WomOrg coaches managed to establish informal networks to reduce the levels of loneliness. For example, Jane described her experience "you get your kind of networks going... [we] worked reasonably closely together ... talk about a game and then we'll go away and have a coffee and talk about ... what we thought about the teams." The informality of the process meant that coaches could talk to a number of other coaches, depending on their availability. Raewyn described her connection with Pat and other coaches. She said:

I think that's probably really important that that channel is open, that I can go to [Pat] while maybe some stage we might actually be applying for the same position; but still that we can go to each other and talk about things and I think that's really important that we're all in the same [boat] for [the sport] as well, just bettering ourselves.

This informal process was reinforced by Anna, who noted that "yes, people buddy up ... there's a fair amount of competitiveness but at the end of the day we're all striving for the same thing." There was some intent on behalf of the organisation to facilitate these connections as, at tournaments, coaches were roomed together if possible. Jackie described the usefulness of this, saying "it was actually nice to have those other coaches that you can shut the door and kick the wall, without it involving the players ... I think that the good part is that when the chips are down they are there for you as well."

Organisational Structures. Neither MixOrg nor WomOrg had a formal structure to the working conditions that fostered the development of relationships between coaches. However, WomOrg's coaches clearly had relationships with other coaches that were very supportive. In addition, the coach manager had an understanding of what the coaches wanted, and was willing to support it, however informally. In contrast, Nick understood developing coaching relationships to mean a one off, formally sanctioned session. This session is thus considered to be a structural feature of MixOrg, but it did not allow the continual, casual interactions between the coaches that were clear in WomOrg. This desire for connection among coaches is consistent with learning and development coaching research on both men and women (e.g., [6, 41-43]. Its importance is further reinforced by Kelchtermans and Ballet's findings [4] in their study of teachers' perceptions of their working conditions. They found that jobs offers from schools with poor relationships among members of the school were often turned down by teachers on the basis of their earlier experiences of the working conditions. Together these findings again reinforce the importance of organisational working conditions that foster interpersonal relationships where there are opportunities to share concerns and discuss work with colleagues [4] and the importance of the social context of coaching [1]. 
Organisational Values. As an organisational value, the relationships between coaches were perceived quite differently between the two organisations. For the MixOrg coaches, interpersonal relationships were perceived as something of a 'holy grail' that might alleviate the loneliness and limited development opportunities for coaches within the organisation. They were seen as something that needed to be organised by MixOrg for them, in part because they did not know each other and thus did not know where to start. This feature may give another insight into the organisation, that is, without common bonds, the coaches looked to the organisation to provide them with support, not to each other. As Hoeber and Frisby [24] noted, however, strong, meaningful organisational values are often those developed by organisational members themselves, rather than handed down by the organisation. Had Nick realised this, he could have encouraged the coaches to work more closely with each other, perhaps fostering informal knowledge networks [44].

In contrast, the WomOrg coaches had taken the initiative to develop and nurture this organisational value. Interestingly, as well as this value being important for them, as coaches, a number noted how protection of knowledge due to the contested nature of sport would be detrimental to the game itself. This maturity ensured that while coaches may well be competitive with each other, both for positions and with regard to results, they were all working towards the betterment of the sport. As such, the organisational value had implications beyond supporting coaches towards the improvement of the sport as a whole. These coaches had fairly well established knowledge networks and had the potential to overcome at least two of the challenges facing the instigation of coaches' communities of practices [42]. First there was an able and enthusiastic facilitator in the coach manager. Second the coaches possessed a willingness to share information. They recognised the benefits of working together and had put aside the potential rivalry amongst coaches that might hinder this process in favour of working for the betterment of themselves and the sport.

Individual Aspects. The working conditions in WomOrg were characterised by well established relationships among coaches that were highly valued and desired by all coaches. In contrast, the coaches in MixOrg felt little or no connection with other coaches. Coaches in both organisations felt that these relationships were not only to help them develop their coaching such as receiving feedback, acting as a sounding board, or mentoring, but also provided the supportive role of 'just being there' for each other. Consistent with SDT [12] these actions are likely to foster working conditions in which coaches support each other and contribute to the satisfaction of the psychological need for relatedness and development of coaching competence.

\section{CONCLUSION}

Coaching is a complex socially situated process and yet little is known about the social context coaches operate within. This study sought to begin to address this issue by examining how women coaches and managers perceived working conditions in their sport organisations. More specifically, as women coaches are under-represented at the higher levels, it is important to understand how this group perceived their working conditions, in order to ensure that sport organisations support women with the intent of increasing their numbers. Consistent with Kelcthermans and Ballet [4] quality interpersonal relationships with other coaches and leaders in the organisation were an important feature of coaches' working conditions. In addition, opportunities for learning and development and being recognised as a person not just a coach were also highly valued.

Organisational structures and values that facilitated and proactively fostered working conditions where quality interpersonal relationships could be developed within the 
organisation positively affected coaches' sense of autonomy support, relatedness, competence, and enthusiasm for working in the organisation. In addition, flexibility in organisational structures and consideration of coaches as individuals with varying strengths and requirements contributed to working conditions that supported coaches' day-to-day activities and continued professional development. Conveying an organisational value around the importance of coach learning and progression combined with organisational structures such as clear development pathways and available educational opportunities contributed to coaches' sense of competence. Where these organisational structures and values were not present in the working conditions of the organisation coaches felt isolated, unsupported, disconnected from the organisation, and valued only for the functional role they could fulfil within the organisation.

This research extends current coaching research in several ways. First, we adopted an interdisciplinary framework to enable us to combine psychological and sociological approaches to analyse the social complexity of coaches' perceptions of their working conditions. Using it, we have noted the similarities and overlap between two approaches that, at first glance, might seem to be quite different. Second, through this framework we were able to describe not only important structural aspects of coaches' working conditions but also how these working conditions were shaped by organisational values and shaped individual need satisfaction. Third, this framework provided the opportunity to examine both managers' and coaches' perspectives, in the creation and sustaining of the organisational working conditions. This is unusual in related research, which has tended to focus on the coaches' views (e.g., [10, 22]) and has largely neglected managers' views.

Finally, many questions remain regarding the social context of coaching. Although our results are not generalisable, researchers may explore the working conditions experienced by men coaches and coaches in different domains of coaching. Such research might examine the working conditions that coaches find both effective and satisfying, the organisations' structures and values that shape these conditions and the influence on coaches' well-being and coaching practice. Furthermore, as Potrac and Jones [12] suggested researchers might also examine how coaches negotiate and work towards achieving favourable working conditions.

Our findings are specific to these organisations and participants and therefore it is not intended that they be generalised to other organisations and coaches. However, based on these findings it is possible to suggest that leaders within sport organisations reflect upon the values and structures within their organisation. The practical implications of this research therefore include the following. First, that leaders and managers consider the structures that they have in place for all coaches. Do coaches have a clear pathway, either fashioned through a national body, or developed by the organisation at a regional or provincial level. If so, do all coaches have access to this pathway, and the support to move along it, particularly if they need mentoring to step to the next level? Second, key organisational personnel could examine the values that are held by coaches within their organisations. They might be surprised to find that those values do not always fit with the accepted 'public' face of an organisation. For example, if women coaches are perceived to be less able than men, because they are women, this would be a value that needs to be critically addressed. A final implication would be to ensure that managers and leaders actively reflect on coaches' working conditions, and that they consider whether the SDT framework is in place. Considering these implications would assist in critically reflecting on the place of all coaches within sport organisations, and would likely encourage decision makers to assess the extent to which the needs of all coaches are met. 


\section{REFERENCES}

1. Jones, R. L., Armour, K. M. and Potrac, P., Understanding the Coaching Process: A Framework for Social Analysis, Quest, 2002, 54, 34-48.

2. Cushion, C. J., Armour, K. M. and Jones, R. L., Locating the Coaching Process in Practice: Models 'for' and 'of' Coaching, Physical Education and Sport Pedagogy, 2006, 11(1), 83-99.

3. Dixon, M. A. and Bruening, J. E., Perspectives on Work-Family Conflict in Sport: An Integrated Approach, Sport Management Review, 2005, 8(3), 227-255.

4. Kelchtermans, G. and Ballet, K., The Micro Politics of Teacher Induction: A Narrative-Biographical Study on Teacher Socialisation, Teaching and Teacher Education, 2002, 18, 105-120.

5. Acosta, R. V. and Carpenter, L. J., Women in Intercollegiate Sport: A Longitudinal Study - Thirty-One Year Update, West Brookfield, MA, 2008.

6. Norman, L., The UK Coaching System is Failing Women Coaches, International Journal of Sports Science and Coaching, 2009, 3(4), 447-476.

7. Reade, I., Rodgers, W. and Norman, L., The Under-Representation of Women in Coaching: A Comparison of Male and Female Canadian Coaches at Low and High Levels of Coaching, International Journal of Sports Science and Coaching, 2009, 4(4), 505-520.

8. Bruening, J. E. and Dixon, M. A., Work-Family Conflict in Coaching II: Managing Role Conflict, Journal of Sport Management, 2007, 21(4), 471-496.

9. Dixon, M. A. and Bruening, J. E., Work-Family Conflict in Coaching I: A Top Down Perspective, Journal of Sport Management, 2007, 21(3), 377-407.

10. Shaw, S. and Hoeber, L., 'A Strong Man is Direct and a Direct Woman is a Bitch': Analysing Discourses of Masculinity and Femininity and their Impact on Employment Roles in Sport Organisations, Journal of Sport Management, 2003,17(4), 347-376.

11. Greenhill, J., Auld, C., Cuskelly, G. and Hooper, S., The Impact of Organisational Factors on Career Pathways for Female Coaches, Sport Management Review, 2009, 12, 229-240.

12. Ryan, R. M. and Deci, E. L., An Overview of Self-Determination Theory: An Organismic-Dialectical Perspective, in: Deci, E. L., and Ryan, R. M., eds., Handbook of Self-Determination Research, University of Rochester Press, New York, 2002, 3-33.

13. Potrac, P. and Jones, R., Power, Conflict, and Cooperation: Toward a Micro Politics of Coaching, Quest, 2009, 61, 223-236.

14. Saury, J. and Durand, M., Practical Knowledge in Expert Coaches: On Site Study of Coaching in Sailing, Research Quarterly for Exercise and Sport, 1998, 69(3), 254-266.

15. Poczwardowski, A., Barott, J. E. and Henschen, K. P., The Athlete and Coach: Their Relationship and its Meaning: Results of an Interpretive Study, International Journal of Sport Psychology, 2002, 33, 116-140.

16. Potrac, P., Jones, R. L. and Armour, K, 'It's All About Getting Respect': The Coaching Behaviours of an Expert English Soccer Coach, Sport Education and Society, 2002, 7(2), 183-202.

17. Gagné, M., The Role of Autonomy Support and Autonomy Orientation in Pro-Social Behavior Engagement, Motivation and Emotion, 2003, 27(3), 199-223.

18. Gagné, M. and Deci, E. L., Self-Determination Theory and Work Motivation, Journal of Organisational Behavior, 2005, 26, 331-362.

19. Stebbings, J., Taylor, I. and Spray, C., Antecedents of Perceived Coach Autonomy Supportive and Controlling Behaviors: Coach Psychological Need Satisfaction and Well-Being, Journal of Sport and Exercise Psychology, 2011, 33, 255-272.

20. Ely, R. J., Foldy, E. G. and Scully, M. A., eds., Reader in Gender, Work, and Organisation, Blackwell, Malden, MA, 2003.

21. Fielding-Lloyd, B. and Meân, L. J., Standards and Separatism: The Discursive Construction of Gender in English Soccer Coach Education, Sex Roles, 2008, 58, 24-39.

22. North, J., Using 'Coach Developers' to Facilitate Coach Learning and Development: Qualitative Evidence From the UK, International Journal of Sports Science and Coaching, 2010, 5(2), 239-256. 
23. Shaw, S. and Penney, D., Gender Equity Policies in National Governing Bodies: An Oxymoron or a Vehicle for Change?, European Sport Management Quarterly, 2003, 3, 78-102.

24. Hoeber, L. and Frisby, W., Gender Equity for Athletes: Rewriting the Narrative for this Organisational Value, European Sport Management Quarterly, 2001, 1, 179-209.

25. Hoeber, L., Gender Equity for Athletes: Multiple Understandings of an Organisational Value, Sex Roles, $2008,58,58-71$.

26. Lyle, J., Sports Coaching Concepts: A Framework for Coaches' Behaviour, Routledge, London, 2002

27. Marshall, D., Developing the Next Generation of Women Coaches, Canadian Journal for Women in Coaching Online, 2001, 1 (4), 1-8.

28. Women's Sports Foundation UK, The Issues Surrounding Women and Coaching, Http://www.wsf.org.uk, accessed 6 April, 2007.

29. LaVoi, N.M. and Dutove, J. K., Barriers and Supports for Female Coaches: An Ecological Model, Sports Coaching Review, 2012, 1(1), 17-37.

30. NZ Olympic Committee, NZ Olympic Team to Beijing, Http://www.olympics.org.nz, accessed 4 September, 2008.

31. New Zealand Olympic Team, Our Team 2012, Http://www.olympic.org.nz/london-2012/officials, accessed 26 October, 2012.

32. Patton, M. Q., Qualitative Evaluation and Research Methods, $2^{\text {nd }}$ edn., Sage, Newberry Park, CA, 2002.

33. Burgess, R. G., ed., Field Research: A Sourcebook and Field Manual, Allen and Unwin, London, 1982.

34. Fontana, A. and Frey, J. H., From Structured Questions to Negotiated Text, in Denzin, N. K., and Lincoln, Y. S., eds., Handbook of Qualitative Research, $2^{\text {nd }}$ edn., Sage, Thousand Oaks, CA, 2000, 645-672.

35. Denzin, N.K. and Lincoln, Y.S., Strategies of Qualitative Inquiry, Sage, Thousand Oaks, 1998.

36. Scully, M. A., Human Resource Management: An Overview, in: Ely, R. J., Foldy, E. G., and Scully, M. A., eds., Reader in Gender, Work, and Organisation, $2^{\text {nd }}$ edn., Blackwell, Malden, MA, 2003, 279-283.

37. Fine, M. G., Building Successful Multicultural Organisations, in: Ely, R. J., Foldy, E. G., and Scully, M. A., eds., Reader in Gender, Work, and Organisation, $2^{\text {nd }}$ edn., Blackwell, Malden, MA, 2003.

38. Kolb, D., Fletcher, J. K., Meyerson, D. E., Merrill-Sands, D. and Ely, R. J., Making Change: A Framework for Promoting Gender Equity in Organisations, in: Ely, R. J., Foldy, E. G., and Scully, M. A., eds., Reader in Gender, Work, and Organisation, $2^{\text {nd }}$ edn., Blackwell, Malden, MA, 2003, 10-15.

39. Deci, E. L., Connell, J. P. and Ryan, R. M., Self-Determination in Work Organisation, Journal of Applied Psychology, 1989, 74, 580-590.

40. Deci, E. L., Eghrari, H., Patrick, B. C. and Leone, D. R., Facilitating Internalization: The Self-Determination Theory Perspective, Journal of Personality, 1994, 62, 119-142.

41. Abraham, A., Collins, D. and Martindale, R., The Coaching Schematic: Validation Through Expert Coach Consensus, Journal of Sports Sciences, 2006, 24(6), 549-564.

42. Irwin, G., Hanton, S. and Kerwin, D. G., Reflective Practice and the Origins of Elite Coaching Knowledge, Reflective Practice, 2004, 5(3), 425-442.

43. Kilty, K., Women in Coaching, The Sport Psychologist, 2006, 20, 222-234.

44. Mallet, C., Becoming a High-Performance Coach: Pathways and Communities, in: Cushion, C., and Lyle, J., eds., Sports Coaching: Professionalisation and Practice, Elsevier, London, 2010, 119-134. 
